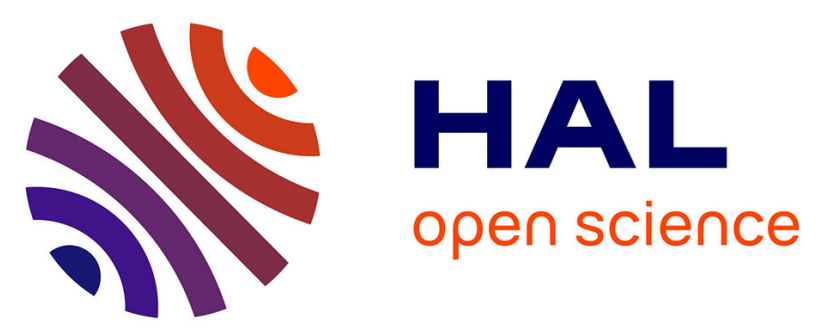

\title{
Wide Cross-species RNA-Seq Comparison Reveals Convergent Molecular Mechanisms Involved in Nickel Hyperaccumulation Across Dicotyledons
}

Vanesa Sanchez Garcia de La Torre, Clarisse Majorel-Loulergue, Guillem J.

Rigaill, Dubiel A. Gonzalez, Ludivine Soubigou-Taconnat, Yohan Pillon, Louise Barreau, Sébastien Thomine, Bruno Fogliani, Valérie

Burtet-Sarramegna, et al.

\section{- To cite this version:}

Vanesa Sanchez Garcia de La Torre, Clarisse Majorel-Loulergue, Guillem J. Rigaill, Dubiel A. Gonzalez, Ludivine Soubigou-Taconnat, et al.. Wide Cross-species RNA-Seq Comparison Reveals Convergent Molecular Mechanisms Involved in Nickel Hyperaccumulation Across Dicotyledons. New Phytologist, 2021, 229 (2), pp.994-1006. 10.1111/nph.16775 . hal-02890477

\section{HAL Id: hal-02890477 \\ https://hal.science/hal-02890477}

Submitted on 20 Nov 2020

HAL is a multi-disciplinary open access archive for the deposit and dissemination of scientific research documents, whether they are published or not. The documents may come from teaching and research institutions in France or abroad, or from public or private research centers.
L'archive ouverte pluridisciplinaire $\mathbf{H A L}$, est destinée au dépôt et à la diffusion de documents scientifiques de niveau recherche, publiés ou non, émanant des établissements d'enseignement et de recherche français ou étrangers, des laboratoires publics ou privés. 


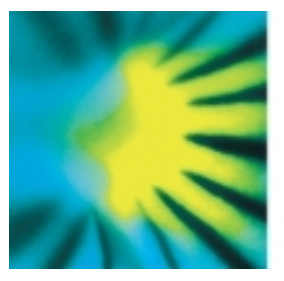

New Phytologist

\section{Wide Cross-species RNA-Seq Comparison Reveals Convergent Molecular Mechanisms Involved in Nickel Hyperaccumulation Across Dicotyledons}

\begin{tabular}{|c|c|}
\hline Journal: & New Phytologist \\
\hline Manuscript ID & NPH-MS-2020-32526.R1 \\
\hline Manuscript Type: & MS - Regular Manuscript \\
\hline $\begin{array}{r}\text { Date Submitted by the } \\
\text { Author: }\end{array}$ & $\mathrm{n} / \mathrm{a}$ \\
\hline Complete List of Authors: & $\begin{array}{l}\text { García de la Torre, Vanesa; I2BC, Cell Biology } \\
\text { Majorel, Clarisse; Univesity of New Caledonia, ISEA } \\
\text { Rigaill, Guillem; IPS2, PMIN; Université d'Evry Val d’Essonne, Laboratoire } \\
\text { de Mathématiques at Modélisation d'Evry (LaMME) } \\
\text { González, Dubiel; Universidad Agraria de La Habana (UNAH), } \\
\text { Department of Biology } \\
\text { Soubigou-Taconnat, Ludivine; Institute of Plant Sciences Paris-Saclay } \\
\text { (IPS2), } 91192 \\
\text { Pillon, Yohan; Institut de recherche pour le developpement, LSTM } \\
\text { Barreau, Louise; I2BC, Cell Biology } \\
\text { Thomine, Sébastien; CNRS, Institute for Integrative Biology of the Cell } \\
\text { (I2BC) } 1 \\
\text { Fogliani, Bruno; Institut Agronomique néo-Calédonien (IAC), Equipe } \\
\text { ARBOREAL; Univesity of New Caledonia, ISEA } \\
\text { Burtet-Sarramegna, Valerie; Univesity of New Caledonia, ISEA } \\
\text { Merlot, Sylvain; CNRS, I2BC }\end{array}$ \\
\hline Key Words: & $\begin{array}{l}\text { Hyperaccumulator, Metal, Nickel, RNA-Seq, IREG/Ferroportin, } \\
\text { Convergence, Noccaea caerulescens }\end{array}$ \\
\hline
\end{tabular}

\section{SCHOLARONE ${ }^{\text {TH }}$ Manuscripts}




\section{Wide Cross-species RNA-Seq Comparison Reveals Convergent Molecular}

\section{Mechanisms Involved in Nickel Hyperaccumulation Across Dicotyledons}

4 Vanesa S. Garcia de la Torre ${ }^{1 \S}$, Clarisse Majorel-Loulergue ${ }^{2}$, Guillem J. Rigaill $3,4,5$, 5 Dubiel A. Gonzalez ${ }^{6}$, Ludivine Soubigou-Taconnat ${ }^{3,5}$, Yohan Pillon ${ }^{7}$, Louise Barreau ${ }^{1}$, 6 Sébastien Thomine ${ }^{1}$, Bruno Fogliani ${ }^{2,8}$, Valérie Burtet-Sarramegna ${ }^{2}$, Sylvain Merlot ${ }^{{ }^{*}}$ 7

1Université Paris-Saclay, CEA, CNRS, Institute for Integrative Biology of the Cell (I2BC), 91198, Gif-sur-Yvette, France.

2Institute of Exact and Applied Sciences (ISEA), Université de la Nouvelle-Calédonie, BP R4, 98851, Nouméa cedex, New Caledonia

12 'Université Paris-Saclay, CNRS, INRAE, Univ Evry, Institute of Plant Sciences Paris13 Saclay (IPS2), 91405, Orsay, France.

14 'Laboratoire de Mathématiques et Modélisation d'Evry (LaMME), Université d'Evry, 15 CNRS, ENSIIE, USC INRAE, 23 bvd de France, 91037, Evry cedex, France

5Université de Paris, CNRS, INRAE, Institute of Plant Sciences Paris-Saclay (IPS2), 91405, Orsay, France

${ }^{6}$ Universidad Agraria de La Habana (UNAH), Departamento de Biologia, 32700, Mayabeque, Cuba

${ }^{7}$ Laboratoire des Symbioses Tropicales et Méditerranéennes (LSTM), IRD, INRAE, CIRAD, Montpellier SupAgro, Univ. Montpellier, 34398, Montpellier cedex, France 8Institut Agronomique néo-Calédonien (IAC), Equipe ARBOREAL, BP 73, 98890, Païta, New Caledonia

\$Present address: Molecular Genetics and Physiology of Plants (MGPP), Faculty of Biology and Biotechnology, Ruhr University Bochum, 44801 Bochum, Germany 
Total word count (w/o summary): 5903

31

Summary: 198

32

Introduction: 802

33

Materials and Methods: 1822

34

Results: 1913

35

Discussion: 1366

36 Number of Figures: 5

37 Fig. 1, Fig. 2, Fig.5 should be published in color

38 Number of tables: 1

39 Supporting Information: Fig: 7; Notes: 1, Tables: 6.

40

41 Keywords: Hyperaccumulator, Metal, Nickel, RNA-Seq, IREG/Ferroportin, 42 Convergence, Noccaea caerulescens. 


\section{Summary}

- The Anthropocene epoch is associated with the spreading of metals in the environment increasing oxidative and genotoxic stress on organisms. Interestingly, about 500 plant species growing on metalliferous soils acquired the capacity to accumulate and tolerate tremendous amount of nickel in their shoots. The wide phylogenetic distribution of these species suggests that nickel hyperaccumulation evolved multiple times independently. However, the exact nature of these mechanisms and whether they have been recruited convergently in distant species is not known.

- To address these questions, we have developed a cross-species RNA-Seq approach combining differential gene expression analysis and cluster of orthologous group annotation to identify genes linked to nickel hyperaccumulation in distant plant families.

- Our analysis reveals candidate orthologous genes encoding convergent function involved in nickel hyperaccumulation, including the biosynthesis of specialized metabolites and cell wall organization. Our data also point out that the high expression of IREG/Ferroportin transporters recurrently emerged as a mechanism involved in nickel hyperaccumulation in plants. We further provide genetic evidence in the hyperaccumulator Noccaea caerulescens for the role of the NcIREG2 transporter in nickel sequestration in vacuoles.

- Our results provide molecular tools to better understand the mechanisms of nickel hyperaccumulation and study their evolution in plants. 


\section{Introduction}

Because of their chemical and biochemical properties, transition metals play fundamental roles in living organisms. However, when present in excess in the environment they induce adverse effects on biological systems producing oxidative and genotoxic stresses or causing secondary deficiency of essential elements because of competition (Waldron et al., 2009; Andresen et al., 2018). Even though they contain metal levels toxic to most plant species, metalliferous soils of geogenic or anthropogenic origin are colonized by specific floras adapted to these high concentrations of metals. While the majority of metallophyte species exclude metals from their tissues, over 700 species have acquired the capacity to accumulate and tolerate tremendous amount of metals in their shoot (van der Ent et al., 2013; Reeves et al., 2018). Plants hyperaccumulating nickel (>1000 mg/kg shoot dry weight) represent, with around 520 species, the vast majority of metal hyperaccumulators (Reeves et al., 2018), likely because of the frequent occurrence of outcrops originating from ultramafic rocks, including serpentine soils, in regions of high biodiversity such as Cuba, New Caledonia or the Mediterranean basin. The large phylogenetic distribution of nickel hyperaccumulators in various plant families further suggest that nickel hyperaccumulation appeared independently several times during plant evolution (Kramer, 2010; Cappa \& Pilon-Smits, 2014). However, whether the mechanisms allowing hyperaccumulation have been recruited convergently or are specific to different plant families is still poorly known.

As for other metals, the hyperaccumulation of nickel requires very efficient uptake by the roots, translocation of nickel to the shoot and its accumulation in leaf cells. The hyperaccumulation of nickel in leaves requires strong detoxification mechanisms involving antioxydant and metal-chelating molecules, as well as the sequestration of nickel in specific compartments (Verbruggen et al., 2009; Kramer, 2010; Clemens, 2019). In most of the cases, nickel is stored in the vacuoles of epidermal cells away from photosynthetic tissues (Küpper et al., 2001; Broadhurst et al., 2004; Bidwell et al., 2004; Mesjasz-Przybylowicz et al., 2016; van der Ent et al., 2019), but nickel enrichment was also observed in the apoplast and cell walls surrounding epidermal cells (Krämer et al., 2000; Bidwell et al., 2004; van der Ent et al., 2019).

In the field of metal hyperaccumulation, most of the molecular studies have been focused on the deciphering of zinc and cadmium accumulation in Brassicaceae species related to A. thaliana. Genetic and transcriptomic studies performed on Arabidopsis halleri and Noccaea caerulescens indicated that metal hyperaccumulation is associated with high and constitutive expression of genes encoding metal transporters, enzymes involved in the biosynthesis of metal chelators and proteins involved in oxidative stress responses 
104 (Becher et al., 2004; Dräger et al., 2004; Weber et al., 2004; Hammond et al., 2006; 105 Shahzad et al., 2010). In A. halleri, it was further shown that knocking down the 106 expression of the highly expressed HEAVY METAL ATPASE 4 transporter gene reduces 107 zinc accumulation, thus demonstrating the essential role of HMA4 in zinc 108 hyperaccumulation (Hanikenne et al., 2008). These data indicated that metal 109 hyperaccumulation essentially evolved from a dysregulation of genes involved in basic 110 mechanisms of metal homeostasis.

111 Despite the essential role of nickel in plants to sustain the activity of urease, our 112 knowledge of the molecular mechanisms involved in nickel homeostasis is still scarce. 113 In Arabidopsis thaliana, members of the IRT/ZIP and IREG/Ferroportin transporter 114 families have been shown to play a role in nickel uptake and distribution (Schaaf et al., 115 2006; Morrissey et al., 2009; Nishida et al., 2011). Furthermore, genes encoding 116 IREG/Ferroportin transporters have been shown to be expressed at higher levels in 117 nickel hyperaccumulators compared to related non-accumulators from the 118 Brassicaceae, Rubiaceae and Asteraceae families (Halimaa et al., 2014; Merlot et al., 119 2014; Meier et al., 2018). A recent transcriptomic study performed in roots of the non120 accumulator $A$. thaliana revealed that high nickel treatment induces the downregulation 121 of genes associated with cell walls, suggesting that the response to high nickel targets 122 cell wall functions (Lešková et al., 2019). In addition, several organic molecules, 123 including histidine, nicotianamine and organic acids, have been shown to form 124 complexes with nickel and have been proposed to play a role in hyperaccumulation 125 (Krämer et al., 1996; Vacchina et al., 2003; Callahan et al., 2012). However, whether 126 these elements participate in the complex nickel hyperaccumulation trait still needs to be 127 supported by functional and genetic evidences.

128 Here, we have developed an RNA-Seq approach combining differential gene expression 129 analysis and cluster of orthologous group (COG) annotation to identify orthologous 130 genes that have been convergently selected in plants to support nickel 131 hyperaccumulation. Our cross-species comparative analysis performed on leaf 132 transcriptomes of a wide diversity of dicotyledon families reveals several COGs 133 associated with nickel hyperaccumulation including genes involved in metal transport, 134 the biosynthesis of specialized metabolites and cell wall organization. We further provide 135 genetic evidence in the nickel hyperaccumulator Noccaea caerulescens that the 136 IREG/Ferroportin transporter NcIREG2 is involved in nickel sequestration into vacuoles. 


\section{Material and Methods}

139 Plant material and sample collection

140 Leaves of nickel hyperaccumulator plants belonging to 5 distinct plant families (Jestrow

141 et al., 2012; Jaffré et al., 2013; Borhidi et al., 2016; Gonneau et al., 2014), Brassicaceae

142 [Noccaea caerulescens subsp. firmiensis (Ncfi)], Cunoniaceae [Geissois pruinosa

143 (Gpru)], Euphorbiaceae [Leucocroton havanensis (Lhav)], Rubiaceae [P. costivenia

144 (Pcos), P. gabriellae (Pgab), Psychotria grandis (Pgra)], Salicaceae [Homalium

145 kanaliense (Hkan)], and leaves of related non-nickel hyperaccumulators, Brassicaceae

146 [N. caerulescens 'Viviez' (Ncviv), N. montana (Nmon)], Cunoniaceae [G. racemosa

147 (Grac)], Euphorbiaceae [Lasiocroton microphyllus (Lmic)], Rubiaceae [P. revoluta

148 (Prev), P. semperflorens (Psem)], Salicaceae [H. betulifolium (Hbet)], were collected on

149 individual plants growing in their natural environment and localized by GPS (Supporting

150 Information Table S1). We complied with local regulation for the access to these genetic

151 resources. For each sample, a fraction of leaves was washed with water and dried for

152 elemental analysis, and the other fraction fixed on site with liquid $\mathrm{N}_{2}$ (Gpru, Grac, Pgab,

153 Psem) or with RNAlater (Sigma Aldrich) and stored at $4^{\circ} \mathrm{C}$ (Ncfi, Ncviv, Nmon, Lhav,

154 Lmic, Pcos, Pgra, Prev, Hkan, Hbet). RNAlater was removed in the laboratory and leaves

155 were immediately stored at $-80^{\circ} \mathrm{C}$ before RNA extraction.

156 Additionally, to generate reference transcriptomes, Ncfi and Nmon were grown in

157 hydroponic condition in a climatic chamber (9 $\mathrm{h}$ light, $150 \mu \mathrm{E} \cdot \mathrm{m}^{-2} \cdot \mathrm{s}^{-1}, 2{ }^{\circ} \mathrm{C} / 17^{\circ} \mathrm{C}$

158 day/night, $70 \%$ humidity) for 7 weeks using a modified Hoagland's solution (Lanquar et

159 al., 2010), containing $20 \mu \mathrm{M}$ Fe-HBED (Van Iperen International) and $37.5 \mu \mathrm{M} \mathrm{NiCl}_{2}$. L.

160 havanensis seeds were cultured in vitro on Murashige \& Skoog Agar medium

161 supplemented with $3.2 \mathrm{mM} \mathrm{NiSO}_{4}$, as described (Gonzalez \& Matrella, 2013).

162 A specimen of Cunonia capensis (Ccap) was obtained from a specialized plant nursery

163 (Ets. Railhet, France) and grown in a green-house on coconut coir supplemented with 164 fertilizer.

165 Phylogenetic analysis

166 Phylogenetic trees of nickel hyperaccumulator and non-accumulator species were 167 constructed with FigTree using the checklist of metal hyperaccumulators from (Reeves 168 et al., 2018), the APG III classification (Chase \& Reveal, 2009) and the plant time169 calibrated tree from (Magallón et al., 2015). Phylogenetic analysis of IREG/FPN protein 170 family was performed with CLC Genomics Workbench v20 software (Qiagen).

\section{RNA sequencing}

172 Total RNA from leaves was extracted with RNeasy Plant Mini kit (Qiagen) for Noccaea 173 species, Qiagen hybrid method for woody plants for Psychotria species from Cuba 
174 (Johnson et al., 2012), CTAB-PVP method for Geissois and Psychotria species from

175 New Caledonia (Johnson et al., 2012), and TRI Reagent (Sigma-Aldrich) for

176 Leucocroton, Lasiocroton and Homalium species. DNA was removed from all RNA

177 samples by RNeasy Plant Mini kit on-column DNase I treatment.

178 RNA quality control, preparation of cDNA libraries, sequencing and raw reads processing 179 were performed by the POPS transcriptomic platform (IPS2, Orsay, France). Libraries 180 were prepared from $1 \mu \mathrm{g}$ of total RNA using TruSeq Stranded mRNA kit (Illumina) and 181 sequenced with an Illumina HiSeq2000 sequencing system in 100bp paired-end mode. 182 Libraries meant to be directly compared were multiplexed and sequenced in a single run. 183 Adaptors and low-quality pair-end sequences were removed from the raw reads and the 184 ribosomal RNA was filtered using the SortMeRNA algorithm (Kopylova et al., 2012). We 185 obtained between 27 and 106 million reads per libraries (Supporting Information Table 186 S2).

187 De novo transcriptome assembly and annotation

188 The transcriptome sequences of Ncfi, Nmon, Pgab, Psem, Pgra, Pcos, Prev, Gpru, Grac, 189 Hkan, Hbet, Lhav and Lmic were obtained independently by de novo assembly of paired190 end reads using CLC Genomics Workbench v9 software (Qiagen). A single library per 191 species was used to minimize genetic variability. Assembly parameters were set as 192 default, except similarity (0.95), length fraction (0.75) and the word size was optimized 193 for each sample (Supporting Information Table S2). The quality of de novo assemblies 194 was assessed by Transrate v1.0.3 using trimmed read sequences (Smith-Unna et al., 195 2016) and BUSCO v4.0.4 using Viridiplantae odb10 lineage dataset (Simão et al., 196 2015). The sequences of the resulting contigs were blasted (Blastx, E-value of $\leq 10 \mathrm{E}-6$ ) 197 against the Viridiplantae protein database (NCBI) and putative function annotated by 198 Gene Ontology (cut-off $=55$; GO weight $=-5$ ) using Blast2GO (Conesa et al., 2005). 199 Filtered contigs for length ( $\geq 200 \mathrm{nt}$ ) and expression (TPKM > 1) were translated for the 200 longest Open Reading Frame. Translated sequences longer than 20 amino acids, 201 together with Arabidopsis thaliana protein sequences (TAIR10, www.arabidopsis.org) 202 were analyzed by OrthoFinder to annotate Clusters of Orthologous Group (COG) (Emms 203 \& Kelly, 2015).

204 Differential gene expression analysis

205 For each pair of species, read count estimation was carried out using CLC Genomics 206 Workbench v9 software by mapping sequencing reads of each sample replicate (default 207 parameters, except similarity: 0.875 and length fraction: 0.75$)$ to the transcriptome of the 208 nickel hyperaccumulator species used as the reference. Statistical analyses to identify 209 Differentially Expressed Genes (DEGs) were performed using the edgeR Bioconductor 
210 package (Robinson et al., 2010). To examine transcript abundance, reads per kilobase

211 million (RPKM) were calculated. To evaluate the influence of the reference

212 transcriptome, we additionally performed swapping analyses using the transcriptome of

213 the non-accumulator species as reference (Supporting Information Table S2). The

214 association of contigs between transcriptomes of a pair of species was established by

215 reciprocal Blast.

216 Multiple-testing analysis

217 Following differential gene expression analyses, we recovered 25,313 COGs containing

218 at least one DEG and collected for each of these COG a number of test statistics (i.e. p-

219 value of all the contigs of this COG) per plant family. We further discarded COGs for

220 which we had test statistics for less than 3 plant families (15,052 COGs), and finally kept

22110,261 COGs to perform the multiple-testing analysis using the Cherry $\mathrm{R}$ package

222 version 0.6-12 (Goeman et al., 2018). We first provided the complete list of the

223 corresponding 121,133 p-values to Cherry and used the Simes inequality with the

224 hommelFast function in R. Then for every COG and plant family, we identified contigs

225 significantly up-regulated $(\mathrm{FC}>2)$ and down-regulated and used Cherry to get a lower

226 bound on the number of $\mathrm{H} 1$ contigs (with a simultaneous $95 \%$ confidence using the

227 pickSimes function in R). For every COG, we counted the number of plant families with

228 at least one up-regulated contig (respectively down-regulated) identified by Cherry.

229 Finally, COGs containing up-regulated or down-regulated contigs in hyperaccumulators

230 species in at least 3 different plant families were selected as candidates COGs

231 associated with nickel hyperaccumulation.

232 Molecular cloning

233 Predicted full-length coding region of NcfilREG2, GpruIREG1 and LhavIREG2 were 234 amplified from leaf cDNAs of the corresponding species, using high-fidelity Phusion 235 polymerase (Thermo Scientific) with gene specific primers containing AttB recombination 236 sequences (Supporting Information Table S6). PCR products were first recombined into 237 pDONOR207 (Invitrogen) and then in pDR195-GTW or pMDC83 for expression in yeast 238 and $N$. caerulescens respectively (Curtis \& Grossniklaus, 2003; Oomen et al., 2008).

239 Artificial miRNA construct targeting NcfilREG2 was designed using the WMD3-Web 240 microRNA Designer (http://wmd3.weigelworld.org). The amiRNA was engineered as 241 previously described (Schwab et al., 2006), by PCR using the pRS300 backbone and 242 specific primers (Supporting Information Table S6). The NcfilREG2-amiRNA precursor 243 was recombined in pDONOR207 and then into the vector pK7GW2D (Karimi et al., 244 2002). All constructs were confirmed by restriction analysis and sequencing.

245 Functional analyses of IREG/Ferroportin in Saccharomyces cerevisiae 
246 IREG/Ferroportin coding regions cloned into pDR195-GTW, as well as pDR195247 AtIREG2 (Schaaf et al., 2006), were transformed by the lithium acetate/PEG method into 248 the Saccharomyces cerevisiae BY4741 strain complemented by a functional HIS3 gene. 249 Yeast sensitivity to nickel was scored by drop assay using serial dilution on histidine-free 250 YNB agar medium containing $20 \mathrm{mM}$ MES ( $\mathrm{pH} 5.5$ ), supplemented or not with $\mathrm{NiCl}_{2}$.

251 Empty pDR195 vector was used as control. Experiments were repeated twice with three 252 independent transformants.

253 Functional analysis of NcfilREG2 in transgenic plants

254 pK7GW2D-NcfilREG2-amiRNA and pMDC83-NcfilREG2 were transformed into $N$. 255 caerulescens subsp. firmiensis by Rhizobium rhizogenes (Arqua1 strain) mediated in 256 vitro root transformation (Lin et al., 2016). Transformed roots were selected using GFP 257 fluorescence under a Leica MZ FLIII Fluorescence Stereo Microscope. Non-transformed 258 roots were cut once a week until the whole root system was transgenic.

259 Independent lines transformed with pK7GW2D-NcfilREG2-amiRNA were then 260 transferred in hydroponic culture as described above for a week and then with the 261 nutrient solution supplemented with $37.5 \mu \mathrm{M} \mathrm{NiCl}_{2}$ for 4 weeks. For each transgenic line, 262 the root system was divided in two samples for RT-qPCR and elemental analysis.

\section{Elemental analysis}

264 Dried environmental leaf samples were mineralized by $\mathrm{HNO}_{3}$. Multi-elemental analyses were performed using ICP-AES (LAMA laboratory, IRD, New Caledonia) or MP-AES.

266 Plant samples from hydroponic cultures were washed twice with ice-cold $10 \mathrm{mM}$ $\mathrm{Na}_{2}$ EDTA and twice with ice-cold ultrapure water. Samples were dried at $65^{\circ} \mathrm{C}$ for 16 hours, weighed and then digested with $70 \% \mathrm{HNO}_{3}$ and $\mathrm{H}_{2} \mathrm{O}_{2}$ for a total of $8 \mathrm{~h}$ with temperature ramping from 80 to $120^{\circ} \mathrm{C}$. Elemental analyses were performed using MP-

270 AES (Agilent 4200, Agilent Technologies) and metal concentration was calculated by

271 comparison with a metal standard solution.

\section{Confocal Imaging}

273 Roots transformed with pMDC83-NcfilREG2 were stained with $10 \mu \mathrm{g} / \mathrm{ml}$ propidium iodide 274 (PI) and imaged on a Leica SP8X inverted confocal microscope (IMAGERIE-Gif 275 platform) with laser excitation at $488 \mathrm{~nm}$ and collection of emitted light at $495-550 \mathrm{~nm}$ 276 for GFP and 600-650 $\mathrm{nm}$ for PI.

277 Quantitative RT-PCR analyses

278 Total RNA from Noccaea species was extracted with RNeasy Plant Mini kit or with TRI

279 Reagent for Ncfi transgenic roots. Total RNA from leaves of Gpru and Ccap was 280 extracted with the CTAB-PVP method as described above. DNA was removed from all 
281 RNA samples by RNeasy Plant Mini kit on-column DNase I treatment. RNA $(1 \mu \mathrm{g})$ were

282 converted to cDNA by random priming using SuperScript III or IV First-Strand reverse

283 transcriptase (Invitrogen) according to the manufacturer's instructions. Quantitative PCR

284 analysis were performed on a LightCycler 96 using LightCycler 480 SYBR Green I

285 Master Mix (Roche) with the following conditions: Initial denaturation $\left(95^{\circ} \mathrm{C}, 300 \mathrm{~s}\right)$,

286 followed by 40 cycles of amplification $\left(95^{\circ} \mathrm{C}, 15 \mathrm{~s} ; 60{ }^{\circ} \mathrm{C}, 15 \mathrm{~s} ; 72{ }^{\circ} \mathrm{C}, 15 \mathrm{~s}\right)$, and a

287 melting curve $\left(95^{\circ} \mathrm{C}, 10 \mathrm{~s} ; 65^{\circ} \mathrm{C}, 30 \mathrm{~s}\right.$ and $\left.95^{\circ} \mathrm{C}, 1 \mathrm{~s}\right)$. Sequence information for Ccap

288 (sample TIUZ) was obtained from the 1KP project (Matasci et al., 2014). Reference

289 genes for Noccaea species (6-phosphogluconate dehydrogenase decarboxylating 3,

290 Nc6PGDH, Ncfi_contig_3009), and Cunoniaceae species (Histone deacetylase 15,

291 GpruHDAC15, Gpru_contig_14406) were selected from our RNA-Seq analyses. Specific

292 primers for IREG/Ferroportin and reference genes were designed to produce amplicons

293 of 100-200 nt (Supporting Information Table S6). Relative gene expression was

294 calculated using the primer efficiency correction method (Pfaffl, 2001). Two technical

295 replicates were used for each sample.

296 General statistics

297 Sample exploration and replication of sequencing data analysis were conducted using

298 limma R package (Ritchie et al., 2015), correlation analyses were conducted by linear

299 regression using generic stats functions of $\mathrm{R}$ software and Heat-map clustering was

300 carried out using heatmap.2 function of the gplots $R$ package (R Development Core

301 Team, 2015).

302 Data availability

303 Raw sequence files, read count files and de novo assembled transcriptomes are publicly

304 available in the NCBl's Gene Expression Omnibus under the SuperSeries accession

305 number GSE116054 or SubSeries accession numbers GSE115411 (Brassicaceae),

306 GSE116051 (Rubiaceae, New Caledonia), GSE116050 (Rubiaceae, Cuba),

307 GSE116048 (Cunoniaceae), GSE116052 (Salicaceae) and GSE116049

308 (Euphorbiaceae). 


\section{Results}

311 Sampling nickel hyperaccumulators from a wide diversity of plant families

312 Nickel hyperaccumulators are found as herbaceous plants, shrubs or trees scattered in

31350 plants families almost exclusively in eudicots (45 families), in both Rosids and

314 Asterids clades (Fig. 1). Some families such as Brassicaceae (87 taxons), Asteraceae

315 (45 taxons) and families of the COM clade comprising Cunoniaceae (48 taxons),

316 Euphorbiaceae (42 taxons) and Salicaceae (38 taxons) are enriched in nickel

317 hyperaccumulators (Jaffré et al., 2013; Reeves et al., 2018). The distribution of nickel

318 hyperaccumulators suggests that this complex trait appeared independently several

319 times during plant evolution but also that some families may have a predisposition to 320 develop this trait.

321 To cover this large diversity, we sampled leaves of 7 nickel hyperaccumulators from 5

322 genera (i.e, Noccaea, Psychotria, Geissois, Homalium, Leucocroton) corresponding to

323 Brassicaceae, Rubiaceae and the families of the COM clade Cunoniaceae, Salicaceae

324 and Euphorbiaceae. These samples have been collected in their natural environment on

325 ultramafic soils in France, New Caledonia and Cuba and the elemental analysis of these

326 samples confirmed the nickel hyperaccumulator status of the corresponding species. For

327 each hyperaccumulator, we also collected leaves of a closely related species or 328 accession not hyperaccumulating nickel (Table 1; Supporting Information Fig. S1, Table

329 S1). Both nickel hyperaccumulators and the corresponding non-hyperaccumulator

330 species were collected in the same geographic area, and when it was possible non-

331 hyperaccumulator species were collected on ultramafic soils (i.e. N. montana, $P$.

332 semperflorens and $H$. betulifolium).

Identification of genes differentially expressed between hyperaccumulators and related non-accumulators

336 To identify genes differentially expressed between nickel hyperaccumulator and closely

337 related non-accumulator species, we performed RNA sequencing (RNA-Seq) using

338 Illumina paired-end technology (Supporting Information Fig. S2). In absence of genomic

339 reference sequences for these species, we assembled de novo the sequence of

340 expressed genes for 13 selected species using short paired-end Illumina reads. These

341 newly generated transcriptomes contain between 41,843 and 87,243 contigs for a total

342 assembly size ranging from $35 \mathrm{Mbp}$ to $49 \mathrm{Mbp}$ and a N50 ranging from 692 to $1735 \mathrm{bp}$

343 (Table 1, Supporting Information Table S2). With the exception of N. montana, these de

344 novo assemblies received a TransRate score ranging from 0.31 to 0.49 and the analysis

345 with BUSCO indicates that they contain from $61 \%$ to $89 \%$ of complete genes with $3 \%$ to 
$3469 \%$ of missing genes (Supporting Information Table S2). These parameters indicate that

347 the quality of these de novo assemblies is in the range of the assemblies usually obtained

348 for plant transcriptomes with this sequencing technology. The significant higher number

349 of contigs and the lower scores obtained for Noccaea montana is likely the result of the

350 allogamous reproduction of $N$. montana increasing genetic diversity and thus affecting

351 de novo assembly. Subsequent annotation of these transcriptomes using Blastx

352 interrogation of Viridiplantae proteins database revealed significant homologies for $56 \%$

353 of the contigs on average $(E-v a l u e \leq 10 E-6)$. These annotated reference transcriptomes

354 constitute a unique and comprehensive resource for molecular studies on plant groups

355 of high interest.

356 The reads from each environmental sample replicates were then mapped to the nickel

357 hyperaccumulator reference transcriptome to identify differentially expressed (DE)

358 genes in 8 pairs of species (or accessions), each containing a hyperaccumulator and a

359 related non-accumulator. The fraction of DE genes ranged from $2 \%$ to $29 \%$ (Fold

360 Change $\geq 2, F D R \leq 0.05$ ), depending on the pair of species considered (Fig. $2 \mathbf{a}$;

361 Supporting Information Fig. S3, Table S4). To evaluate the influence of the choice of the

362 reference transcriptome, we performed swapping analysis. To perform this analysis, we

363 calculated the read count for each contig using the transcriptome of the non-accumulator

364 species as reference and we performed the same transcriptomic comparison as before.

365 We then compared the fold change of the contigs obtained with the hyperaccumulator

366 and the non-accumulator transcriptomes successively used as references (Supporting

367 Information Fig. S4). This analysis revealed that the results were strongly correlated in

368 most pair of species $(r=0.81-0.85$; P-value $<0.05)$. The lower correlation $(r=0.70)$

369 obtained when using the non-accumulator $N$. montana transcriptome as reference is

370 likely the result of the lower quality of the transcriptome assembly for this species.

371 Overall, the results indicated that the choice of the reference transcriptome when

372 studying closely related species had only a marginal influence on the identification of DE

373 genes.

375 Identification of biological functions associated with nickel hyperaccumulation in distant 376 families

377 To determine if dysregulated molecular and metabolic pathways are shared by nickel 378 hyperaccumulators from distant plant families, it was necessary to compare their 379 transcriptomes altogether with a functional emphasis. To this aim, we classified the gene 380 products into Clusters of Orthologous Groups (COG). Combining the 13 reference 381 transcriptomes, 443,400 contigs (66.5\% of total) were assigned to 46,458 COGs 
382 (Supporting Information Table S3), and 25,313 COGs included at least one DE gene in 383 one plant family. Following the differential gene expression analysis in the different plant 384 families, we performed a multiple-testing analysis at the COGs level using the R Cherry package (Goeman \& Solari, 2011). We selected up-regulated and down-regulated COGs containing genes more expressed, and less expressed respectively, in hyperaccumulators from at least 3 different plant families. This analysis revealed 26 groups, including 15 up-regulated COGs and 11 down-regulated COGs (Fig. 2b; Supporting Information Table S5). The functional annotation of these COGs indicated that the most represented categories in up-regulated COGs (Fig. 2b, c) correspond to class I transposable elements (TEs), known as retrotransposons and to genes involved in the biosynthesis and metabolism of specialized metabolites. In addition to organic acids and nitrogen/oxygen ligands (e.g. histidine and nicotianamine acid) that are known nickel ligands, more recent studies have highlighted the role of the phenylpropanoid compounds coumarins and flavonoids as potential metal ligands involved in metal transport, tolerance and accumulation in plants (Kasprzak et al., 2015; Tsai \& Schmidt, 2017; Corso et al., 2018). Therefore, the high expression of genes coding for enzymes involved in the biosynthesis of specific metabolites such as UDPglucose:anthocyanidin/flavonol

3-O-glucosyltransferase

(COG

35) or BAHD acyltransferase (COG 44) could therefore lead to an increased synthesis of metal ligands in nickel hyperaccumulators.

On the other hand, the most represented categories in down-regulated COGs correspond to genes involved in response to stress and in cell wall biogenesis or organization (Fig. 2d). This latter category includes COGs corresponding to expansin (COG 75), xyloglucan endotransglucosylase/hydrolase (COG 109) and pectin acetylesterase (COG 423). Because of their capacity to bind positively charged metals, cell walls may regulate the apoplastic mobility of metals or be a reservoir for metals in nickel hyperaccumulators (Krämer et al., 2000; Krzesłowska, 2011; Le Gall et al., 2015). However, it is difficult to predict the consequences of a reduced expression of these genes on cell wall properties regarding metals binding in nickel hyperaccumulators.

The high expression of IREG/Ferroportin transporters in leaves has a conserved function in nickel hyperaccumulation

414 Our analysis points to IREG/Ferroportin transporters (COG 1981) as some of the most 415 robustly up-regulated function associated with nickel hyperaccumulation in several plant 416 families (Fig. 2c; Supporting Information Table S5). Phylogenetic analysis revealed that 417 Brassicaceae species, including $N$. caerulescens, contain 2 gene clusters, represented 
418 by $A$. thaliana IREG1 and IREG2, belonging to COG 1981 (Supporting Information Fig.

419 S5). These transporters were shown to localize on different membranes and therefore 420 proposed to play distinct functions in metal transport (Schaaf et al., 2006; Morrissey et 421 al., 2009). In several species from the Euphorbiaceae, Salicaceae, Cunoniaceae and 422 Rubiaceae families, we also observe a duplication of IREG/Ferroportin genes. However, 423 these transporters do not cluster with AthalREG1 or AthaIREG2 and it is therefore not 424 possible to infer their specific function. Genes encoding IREG/Ferroportin transporters 425 are significantly more expressed (from 4 to 800 -fold increase) in several nickel 426 hyperaccumulator species from the Brassicaceae, Rubiaceae and Euphorbiaceae 427 families compared to their related non-accumulator species. Very recently, the high 428 expression in leaves of an IREG/Ferroportin gene from the Asteraceae species Senecio 429 coronatus was associated with the capacity to hyperaccumulate nickel (Meier et al., 430 2018). Together, these results strongly support the hypothesis that the high expression 431 of IREG/Ferroportin in leaves may play an essential and conserved role in nickel 432 hyperaccumulation in a wide diversity of plant families in both Asterid and Rosid clades.

433 In the selected pairs of species of the Salicaceae and Cunoniaceae families originating 434 from New Caledonia, we did not detect differential expression of IREG/Ferroportin genes 435 (Fig. 2c). However, the analysis of our RNA-Seq data indicates that IREG/Ferroportin 436 genes are highly expressed in both hyperaccumulator and non-accumulator species 437 from these families compared to non-accumulators from Brassicaceae and 438 Euphorbiaceae families (Supporting Information Fig. S6a). Furthermore, the unique 439 IREG/Ferroportin gene (COG 1981) detected in the hyperaccumulator Geissois pruinosa 440 is 60-times more expressed than its orthologue in the non-accumulator Cunoniaceae 441 species Cunonia capensis from South Africa (Supporting Information Fig. S6b). The high 442 expression of IREG/Ferroportin genes in non-accumulator species endemic to New 443 Caledonia might be a genetic footprint of nickel tolerance and hyperaccumulation caused 444 by the recent ( $<35 \mathrm{Ma}$ ) colonization of this island then probably fully covered by an 445 ultramafic rock layer rich in nickel (Pillon et al., 2010, 2014). After adaptive radiation, 446 some species that have colonized more recently exposed non-ultramafic areas might 447 have lost some of the important functions necessary for the full expression of the nickel 448 tolerance and hyperaccumulation traits while still expressing IREG/Ferroportin at high 449 levels.

451 IREG/Ferroportin transporters have a conserved function in vacuolar sequestration of 452 nickel in hyperaccumulators 
453 To provide functional evidence for the conserved role of plant IREG/Ferroportin in nickel 454 hyperaccumulation, we expressed in yeast IREG/Ferroportin orthologs cloned from 3 455 nickel hyperaccumulators from the distant families Brassicaceae, Cunoniaceae and 456 Euphorbiaceae (Fig. 3). The expression of these transporters increases yeast resistance 457 to nickel. These results are consistent with a conserved function of plant 458 IREG/Ferroportin as metal exporters, driving nickel out of the cytosol in the extracellular 459 medium or in intracellular stores and thus reducing cytosolic toxicity.

460 We then wanted to investigate the biological function of IREG/Ferroportin in nickel 461 hyperaccumulation in planta using Noccaea caerulescens as a model. We chose to 462 target NcIREG2, the ortholog of Arabidopsis thaliana IREG2, because it shows the 463 strongest expression in both shoot and roots of the nickel hyperaccumulator $N$. 464 caerulescens subsp. firmiensis when compared with the non-accumulator Noccaea 465 caerulescens 'Viviez' (Fig. 4; Supporting Information Table S4). We first used Rhizobium 466 rhizogenes root transformation to express a C-terminal GFP tagged version of 467 NcfilREG2 in N. caerulescens subsp. firmiensis. NcfilREG2-GFP is able to complement 468 the nickel hypersensitive phenotype of the $A$. thaliana ireg2 mutant indicating that this 469 fusion protein is functional (Supporting Information Fig. S7). Confocal imaging of $N$. 470 caerulescens transgenic roots shows that NcfilREG2-GFP localizes on the membrane 471 of the vacuole suggesting a role of this transporter in nickel storage in this intracellular 472 compartment (Fig. 5a). To support this hypothesis, we used the same transformation 473 strategy to silence the expression of NcfilREG2 using artificial amiRNA technology. We 474 generated 8 independent composite transgenic lines displaying different degrees of 475 NcfilREG2 silencing (Fig. 5b). Elemental analysis of these transgenic lines revealed a 476 decrease of nickel concentration in roots that strongly correlates $\left(R^{2}=0.97, P\right.$-value $<$ 477 0.001) with NcfilREG2 expression (Fig. 5c). In contrast, the concentration of nickel in the 478 shoots of these lines does not correlate with NcfilREG2 expression in roots $\left(R^{2}=0.45\right)$. 479 Together, these results provide evidences that NcfilREG2 contributes to the 480 accumulation of nickel in the roots of Noccaea caerulescens subsp. firmiensis by driving 481 nickel sequestration in vacuoles. However, the expression of NcIREG2 in roots does not 482 seem to be a limiting factor for the transport of nickel to the shoot in $N$. caerulescens 483 subsp. firmiensis. 


\section{Discussion}

486 The development of RNA-Seq technologies has opened the possibility to study non-

487 model species at the molecular level. Yet, comparative biology has not fully benefited

488 from this revolution because of the difficulty to quantitatively compare transcriptomes

489 from distant species (Roux et al., 2015). In this study, we have used a combination of

490 cross-species comparative transcriptomics analysis, COG annotation and multiple-

491 testing analysis to identify genes associated with nickel hyperaccumulation in a wide

492 diversity of plant families. While pairwise comparisons between a nickel

493 hyperaccumulator and a related non-hyperaccumulator species identified a high number

494 of candidate DE genes, it is expected that a large proportion of these candidate DE

495 genes are not directly linked to the nickel hyperaccumulation trait but also to other traits

496 differentiating these species. On the other hand, pairwise comparison of closely related

497 species or accessions with a distinctive hyperaccumulation phenotype may also fail to

498 reveal mechanisms involved in this multigenic trait as for example observed for IREG/

499 Ferroportin genes in Geissois species from New Caledonia (Fig. 2c, Fig. S6). Thus, we

500 focused our analyses on the identification of convergent mechanisms between families

501 (Fig. 2a; Supporting Information Fig. S3). This strategy allowed the identification of a

502 limited number of candidate DE genes playing a conserved function in nickel

503 hyperaccumulation. This strategy may fail to identify molecular mechanisms specific to

504 a group of plants (e.g. family, genus). However, a similar approach could likely be used

505 to identify such specific mechanisms but would require to increase the number of species

506 within this group.

508 The high expression of IREG/Ferroportin transporters was previously linked to nickel 509 hyperaccumulation in Brassicaceae and Asteraceae species (Halimaa et al., 2014; Meier 510 et al., 2018). Our results support these findings and further indicates that 511 IREG/Ferroportin transporters have been recurrently recruited as a convergent 512 mechanism for nickel hyperaccumulation in a wide diversity of plant species. It is also 513 interesting to notice that we did not identify other families of metals transporters 514 suggesting that, besides IREG/Ferroportin, diverse metal transporter families may have 515 been recruited to support other important steps of nickel accumulation in leaves of distant 516 hyperaccumulator species. Importantly, this result a posteriori validates our cross517 species comparative approach to identify genes playing a convergent role in nickel 518 hyperaccumulation.

519 Our results also point to a convergent role for several functions involved in the biogenesis 520 and organization of cell walls and in the synthesis of specialized metabolites (Fig. 2c,d). 
521 The high expression of several genes involved in the metabolism of phenylpropanoid 522 compounds is linked to the hyperaccumulation trait in several families. Coumarins and 523 flavonoids have the capacity to bind metals and have been previously linked to iron 524 nutrition and cadmium accumulation (Kasprzak et al., 2015; Tsai \& Schmidt, 2017; Corso 525 et al., 2018). These results suggest that nickel hyperaccumulators synthesize 526 specialized metabolites involved in the detoxification and transport of nickel. However, 527 the functional annotation of the selected COGs does not allow to pinpoint specific 528 pathways. Comparative metabolomic analyses of nickel hyperaccumulator and related 529 non-accumulator species may identify specialized metabolites associated with nickel 530 hyperaccumulation and therefore establish a direct link between identified COGs and 531 specialized metabolites biosynthetic pathways. A recent report showed that the excess

532 of nickel in $A$. thaliana leads to a reduced expression of genes associated with cell walls 533 of root cells (Lešková et al., 2019). Accordingly, we observed a lower expression of 534 COGs associated with cell wall in several hyperaccumulator species. Interestingly, our analysis also revealed the up-regulation of COG 19, corresponding to the cell wallassociated kinase family (WAKL) in nickel hyperaccumulators (Fig. 2c). The expression of members of the WAKL family has been shown to be induced by metals in plants and the increased expression of WAKL4 in A. thaliana increases tolerance to nickel (Hou et al., 2005). Together, these results suggest that a modification of the cell wall structure, at least in specific tissues, could play a conserved role in nickel tolerance and hyperaccumulation in plants.

542 We also identified several COGs corresponding to Class I retrotransposon up-regulated in nickel hyperaccumulating species. The expression of these elements is known to be responsive to stress conditions and their transposition can generate several types of mutations that can result in the inactivation of gene function or in increased gene expression by cis-addition (Casacuberta \& González, 2013; Makarevitch et al., 2015). In the metal hyperaccumulator species $A$. halleri, Class I retrotransposons are linked to the triplication of the HMA4 gene and may account for the high expression of this metal transporter essential for zinc hyperaccumulation (Hanikenne et al., 2008). It is therefore tempting to speculate that transposable elements are involved in the evolution of the nickel hyperaccumulation trait by altering the activity of some important genes.

Although metal hyperaccumulators are not easily amenable to genetic engineering, molecular genetic studies are necessary to demonstrate the role of candidate genes in

555 this complex trait (Hanikenne et al., 2008). To support the essential role of 556 IREG/Ferroportin in nickel accumulation, we performed molecular and genetic studies in roots of the hyperaccumulator $N$. caerulescens subsp. firmiensis (Fig. 5). These results 
demonstrated that NcfilREG2 localizes on the vacuole and that decreasing NcfilREG2 expression in roots strongly affects nickel accumulation (Fig. 5b). These results provide

560 a genetic evidence supporting a role of NcIREG2 in the storage of nickel in the vacuoles

561 of $N$. caerulescens cells. Surprisingly, the silencing of NcIREG2 in roots did not lead to 562 a significant increase in nickel accumulation in leaves (Fig. 5c). This result might appear as counterintuitive because the sequestration of metals in root cells has been proposed to be a factor limiting their translocation and therefore their accumulation in the shoot of hyperaccumulators. Our results rather suggest that the expression of NcIREG2 in roots of $N$. caerulescens subsp. firmiensis is not a factor limiting the hyperaccumulation of nickel in leaves. This conclusion is further supported by the parallel comparison of NcIREG2 expression and nickel accumulation in N. caerulescens subsp. firmiensis and $N$. caerulescens 'Viviez'. This analysis indicates that there is no negative correlation between the expression of NcIREG2 in roots and the capacity to accumulate nickel in shoots (Fig. 4). This conclusion does not rule out that the expression of NcIREG2 in roots may limit the translocation of nickel to shoots in other Noccaea accessions or species such as $N$. montana (Fig. 4) or N. japonica as very recently proposed (Nishida et al., 2020). In contrast, the high expression of NcIREG2 and the consecutive sequestration of nickel in shoots might create a sink effect favoring the transfer of nickel from roots to shoots in $N$. caerulescens subsp. firmiensis. To directly demonstrate the major role of NcIREG2 in nickel hyperaccumulation, it will be necessary to further develop transformation protocols of $N$. caerulescens to modify the expression of this gene in shoots.

580 Based on our wide cross-species transcriptomic analysis and functional evidences obtained in transgenic $N$. caerulescens, we propose that IREG/Ferroportin transporters play a conserved and essential role in the storage of nickel in the vacuole of leaf cells in a wide range of nickel hyperaccumulating species. This role was previously proposed for the transporter PgIREG1 from the nickel hyperaccumulator P. gabriellae (Merlot et al., 2014). However, we cannot completely exclude that some IREG/Ferroportin orthologues differentially expressed in hyperaccumulators might localize on the plasma membrane to transport nickel out of cells as this was proposed for the $A$. thaliana IREG1 transporter (Morrissey et al., 2009). In the context of nickel hyperaccumulation, these transporters might facilitate cell-to-cell transport of nickel or transport nickel out of epidermal cells

590 leading to its accumulation in the cell walls (Krämer et al., 2000; van der Ent et al., 2019).

591 In the context of sustainable development, nickel hyperaccumulators are now viewed as

592 crops to extract and recycle metals from large areas of metalliferous soils (Grison, 2015;

593 Nkrumah et al., 2016). As for other crops, we foresee that the molecular knowledge

594 obtained in our study could become instrumental for marker-assisted selection of 
595 cultivars or molecular monitoring of agricultural practices to improve nickel 596 phytoextraction. This work provides a framework to identify additional key genes from 597 root transcriptomes involved in the efficient uptake and translocation of nickel to the 598 leaves. The identification of all molecular steps from uptake in roots to sequestration in 599 leaves is necessary to fully understand this complex trait. 


\section{Acknowledgments}

602 We thank professor Rosalina Berazaín Iturralde (JBN, Cuba) for invaluable information 603 on the Cuban flora, Louis-Charles Brinon (IAC, New Caledonia) for sample collection in 604 New Caledonia, Christelle Espagne for technical assistance, Véronique Brunaud and 605 Marie-Laure Martin-Magniette (IPS2, France) for guidance on de novo assembly and 606 biostatistical analysis, and Mark G. M. Aarts (WUR, Netherlands) for the Noccaea root 607 transformation protocol.

608 This work was supported by Grants ANR-13-ADAP-0004 (SM, BF, VBS) and CNRS Defi 609 Enviromics Gene-4-Chem to SM, a SCAC fellowship from the French Embassy in Cuba 610 to DAG and SM and an ATIGE grant from Genopole to GJR. This work has benefited 611 from the core facilities of Imagerie-Gif, a member of Infrastructures en Biologie Santé et 612 Agronomie (IBiSA), supported by France Biolmaging Grant ANR-10INBS-04-01 and the 613 Saclay Plant Science Labex Grant ANR-11-IDEX-0003-0. The POPS platform benefits 614 from the support of the LabEx Saclay Plant Sciences-SPS (ANR-10-LABX-0040-SPS). 615 We thank the South Province of New Caledonia and the Prefecture of Aveyron for plant 616 collection authorizations.

\section{Author contributions}

619 BF, VBS and SM designed the project; VSG, CML, DAG, BF, VBS and SM collected 620 plant samples; VSG, CML, DAG, LB performed experiments; LST supervised RNA-Seq 621 sequencing; VSG, GJR, YP, ST and SM analyzed the data; VSG, ST and SM wrote the 622 manuscript; all authors commented and approved the content of the manuscript. 
Andresen E, Peiter E, Kupper H. 2018. Trace metal metabolism in plants. Journal of

626 Experimental Botany 69: 909-954.

627 Becher M, Talke IN, Krall L, Krämer U. 2004. Cross-species microarray transcript 628 profiling reveals high constitutive expression of metal homeostasis genes in shoots of 629 the zinc hyperaccumulator Arabidopsis halleri. Plant Journal 37: 251-268.

630 Bidwell SD,Crawford SA, Woodrow IE, Sommer-Knudsen J, Marshall AT. 2004.

631 Sub-cellular localization of $\mathrm{Ni}$ in the hyperaccumulator, Hybanthus floribundus (Lindley)

632 F. Muell. Plant, Cell \& Environment 27: 705-716.

633 Borhidi AL, Oviedo-Prieto R, Fernández-Zequeira M. 2016. Nuevos resultados de la 634 revisión taxonómica de los géneros Palicourea y Psychotria (Rubiaceae, Psuchotrieae) 635 en Cuba. Acta Botanica Hungarica 58: 1-48.

636 Broadhurst CL, Chaney RL, Angle JS, Erbe EF, Maugel TK. 2004. Nickel localization 637 and response to increasing Ni soil levels in leaves of the Ni hyperaccumulator Alyssum 638 murale. Plant and Soil 265: 225-242.

639 Callahan DL, Roessner U, Dumontet V, De Livera AM, Doronila A, Baker AJ, Kolev 640 SD. 2012. Elemental and metabolite profiling of nickel hyperaccumulators from New 641 Caledonia. Phytochemistry 81: 80-89.

642 Cappa JJ, Pilon-Smits EA. 2014. Evolutionary aspects of elemental 643 hyperaccumulation. Planta 239: 267-275.

644 Casacuberta E, González J. 2013. The impact of transposable elements in 645 environmental adaptation. Molecular Ecology 22: 1503-1517.

646 Chase MW, Reveal JL. 2009. A phylogenetic classification of the land plants to 647 accompany APG III. Botanical Journal of the Linnean Society 161: 122-127.

648 Clemens S. 2019. Metal ligands in micronutrient acquisition and homeostasis. Plant, 649 Cell \& Environment 42: 2902-2912.

650 Conesa A, Götz S, García-Gómez JM, Terol J, Talón M, Robles M. 2005. Blast2GO:

651 A universal tool for annotation, visualization and analysis in functional genomics 652 research. Bioinformatics 21: 3674-3676.

653 Corso M, Schvartzman MS, Guzzo F, Souard F, Malkowski E, Hanikenne M, 654 Verbruggen N. 2018. Contrasting cadmium resistance strategies in two metallicolous 655 populations of Arabidopsis halleri. New Phytologist 218: 283-297.

656 Curtis MD, Grossniklaus U. 2003. A Gateway Cloning Vector Set for High-Throughput 657 Functional Analysis of Genes in Planta 133 : 462-469.

658 Dräger DB, Desbrosses-Fonrouge AG, Krach C, Chardonnens AN, Meyer RC, 659 Saumitou-Laprade P, Krämer U. 2004. Two genes encoding Arabidopsis halleri MTP1 
660

661

662

663

664

665

666

667

668

669

670

671

672

673

674

675

676

677

678

679

680

681

682

683

684

685

686

687

688

689

690

691

692

693

694

695

696

metal transport proteins co-segregate with zinc tolerance and account for high MTP1 transcript levels. Plant J 39: 425-439.

Emms DM, Kelly S. 2015. OrthoFinder: solving fundamental biases in whole genome comparisons dramatically improves orthogroup inference accuracy. Genome Biology 16: $1-14$.

van der Ent A, Baker AJM, Reeves RD, Pollard AJ, Schat H. 2013. Hyperaccumulators of metal and metalloid trace elements: Facts and fiction. Plant and Soil 362: 319-334.

van der Ent A, Spiers KM, Brueckner D, Echevarria G, Aarts MGM, MontargèsPelletier E. 2019. Spatially-resolved localization and chemical speciation of nickel and zinc in Noccaea tymphaea and Bornmuellera emarginata. Metallomics 11: 2052-2065.

Le Gall H, Philippe F, Domon J-M, Gillet F, Pelloux J, Rayon C. 2015. Cell Wall Metabolism in Response to Abiotic Stress. Plants 4: 112-166.

Goeman JJ, Solari A. 2011. Multiple Testing for Exploratory Research. Statistical Science 26: 584-597.

Goeman JJ, Solari A, Meijer RJ. 2019. Cherry: Multiple testing methods for exploratory research $R$ package version 0.6-13.

Gonneau C, Genevois N, Frerot H, Sirguey C, Sterckeman T. 2014. Variation of trace metal accumulation, major nutrient uptake and growth parameters and their correlations in 22 populations of Noccaea caerulescens. Plant and Soil 384: 271-287.

Gonzalez DA, Matrella S. 2013. Nickel hyperaccumulation 'in vitro' by Leucocroton havanensis (Euphorbiaceae). Revista del Jardín Botánico Nacional 34-35: 83-88.

Grison C. 2015. Combining phytoextraction and ecocatalysis: a novel concept for greener chemistry, an opportunity for remediation. Environmental Science and Pollution Research 22: 5589-5591.

Halimaa P, Lin YF, Ahonen VH, Blande D, Clemens S, Gyenesei A, Haikio E, Karenlampi SO, Laiho A, Aarts MG, et al. 2014. Gene expression differences between Noccaea caerulescens ecotypes help to identify candidate genes for metal phytoremediation. Environmental Science \& Technology 48: 3344-3353.

Hammond JP, Bowen H, White PJ, Mills V, Pyke KA, Baker AJM, Whiting SN, May ST, Broadley MR. 2006. A comparison of Thlaspi caerulescens and Thlaspi arvense shoot transcriptomes. New Phytologist 170: 239-260.

Hanikenne M, Talke IN, Haydon MJ, Lanz C, Nolte A, Motte P, Kroymann J, Weigel D, Krämer U. 2008. Evolution of metal hyperaccumulation required cis-regulatory changes and triplication of HMA4. Nature 453: 391-395.

Hou X, Tong H, Selby J, DeWitt J, Peng X, He Z-H. 2005. Involvement of a Cell WallAssociated Kinase, WAKL4, in Arabidopsis Mineral Responses. Plant Physiology 139: 

1704-1716.

698 Jaffré T, Pillon Y, Thomine S, Merlot S. 2013. The metal hyperaccumulators from New 699 Caledonia can broaden our understanding of nickel accumulation in plants. Frontiers in 700 plant science 4: 279.

701 Jestrow B, Gutiérrez Amaro J, Francisco-Ortega J. 2012. Islands within islands: A 702 molecular phylogenetic study of the Leucocroton alliance (Euphorbiaceae) across the 703 Caribbean Islands and within the serpentinite archipelago of Cuba. Journal of 704 Biogeography 39: 452-464.

705 Johnson MTJ, Carpenter EJ, Tian Z, Bruskiewich R, Burris JN, Carrigan CT, Chase 706 MW, Clarke ND, Covshoff S, DePamphilis CW, et al. 2012. Evaluating Methods for 707 Isolating Total RNA and Predicting the Success of Sequencing Phylogenetically Diverse 708 Plant Transcriptomes. PLoS ONE 7: e50226.

709 Karimi M, Inzé D, Depicker A. 2002. GATEWAYTM vectors for Agrobacterium-mediated 710 plant transformation. Trends in Plant Science 7: 193-195.

711 Kasprzak MM, Erxleben A, Ochocki J. 2015. Properties and applications of flavonoid 712 metal complexes. RSC Advances 5: 45853-45877.

713 Kopylova E, Noé L, Touzet H. 2012. SortMeRNA: Fast and accurate filtering of 714 ribosomal RNAs in metatranscriptomic data. Bioinformatics 28: 3211-3217.

715 Krämer U. 2010. Metal hyperaccumulation in plants. Annual Review of Plant Biology 61: 716 517-534.

717 Krämer U, Cotter-Howells JD, Charnock JM, Baker AJM, Smith JAC. 1996. Free 718 histidine as a metal chelator in plants that accumulate nickel. Nature 379: 635-638.

719 Krämer U, Pickering IJ, Prince RC, Raskin I, Salt DE. 2000. Subcellular localization 720 and speciation of nickel in hyperaccumulator and non-accumulator Thlaspi species. 721 Plant physiology 122: 1343-1353.

722 Krzesłowska M. 2011. The cell wall in plant cell response to trace metals: 723 polysaccharide remodeling and its role in defense strategy. Acta Physiologiae Plantarum 724 33: 35-51.

725 Küpper H, Lombi E, Zhao FJ, Wieshammer G, McGrath SP. 2001. Cellular 726 compartmentation of nickel in the hyperaccumulators Alyssum lesbiacum, Alyssum 727 bertolonii and Thlaspi goesingense. J Exp Bot 52: 2291-2300.

728 Lanquar V, Ramos MS, Lelièvre F, Barbier-Brygoo H, Krieger-Liszkay A, Krämer U, 729 Thomine S. 2010. Export of Vacuolar Manganese by AtNRAMP3 and AtNRAMP4 Is 730 Required for Optimal Photosynthesis and Growth under Manganese Deficiency. Plant 731 Physiology 152: 1986-1999.

732 Lešková A, Zvarík M, Araya T, Giehl RFH. 2019. Nickel Toxicity Targets Cell Wall733 Related Processes and PIN2-Mediated Auxin Transport to Inhibit Root Elongation and 
734 Gravitropic Responses in Arabidopsis. Plant and Cell Physiology 0: 1-17.

735 Lin YF, Hassan Z, Talukdar S, Schat H, Aarts MG. 2016. Expression of the ZNT1 Zinc

736 Transporter from the Metal Hyperaccumulator Noccaea caerulescens Confers

737 Enhanced Zinc and Cadmium Tolerance and Accumulation to Arabidopsis thaliana.

738 PLOS ONE 11: e0149750.

739 Magallón S, Gómez-Acevedo S, Sánchez-Reyes LL, Hernández-Hernández T. 2015.

740 A metacalibrated time-tree documents the early rise of flowering plant phylogenetic 741 diversity. New Phytologist 207: 437-453.

742 Makarevitch I, Waters AJ, West PT, Stitzer M, Hirsch CN, Ross-Ibarra J, Springer

743 NM. 2015. Transposable Elements Contribute to Activation of Maize Genes in Response

744 to Abiotic Stress. PLOS Genetics 11: 1-12.

745 Matasci N, Hung L, Yan Z, Carpenter EJ, Wickett NJ, Mirarab S, Nguyen N, Warnow

746 T, Ayyampalayam S, Barker M, et al. 2014. Data access for the 1, 000 Plants ( 1KP )

747 project. GigaScience 3: 1-17.

748 Meier SK, Adams N, Wolf M, Balkwill K, Muasya AM, Gehring CA, Bishop JM, Ingle

749 RA. 2018. Comparative RNA-seq analysis of nickel hyperaccumulating and non-

750 accumulating populations of Senecio coronatus (Asteraceae). The Plant Journal 95:

751 1023-1038.

752 Merlot S, Hannibal L, Martins S, Martinelli L, Amir H, Lebrun M, Thomine S. 2014.

753 The metal transporter PgIREG1 from the hyperaccumulator Psychotria gabriellae is a

754 candidate gene for nickel tolerance and accumulation. Journal of Experimental Botany 755 65: 1551-1564.

756 Mesjasz-Przybylowicz J, Przybylowicz W, Barnabas A, van der Ent A. 2016.

757 Extreme nickel hyperaccumulation in the vascular tracts of the tree Phyllanthus balgooyi

758 from Borneo. New Phytologist 209: 1513-1526.

759 Morrissey J, Baxter IR, Lee J, Li L, Lahner B, Grotz N, Kaplan J, Salt DE, Guerinot

760 ML. 2009. The ferroportin metal efflux proteins function in iron and cobalt homeostasis

761 in Arabidopsis. Plant Cell 21: 3326-3338.

762 Nishida S, Tsuzuki C, Kato A, Aisu A, Yoshida J, Mizuno T. 2011. AtIRT1, the primary 763 iron uptake transporter in the root, mediates excess nickel accumulation in Arabidopsis

764 thaliana. Plant Cell Physiology 52: 1433-1442.

765 Nishida S, Tanikawa R, Ishida S, Yoshida J, Mizuno T, Nakanishi H, Furuta N. 2020.

766 Elevated Expression of Vacuolar Nickel Transporter Gene IREG2 Is Associated With

767 Reduced Root-to-Shoot Nickel Translocation in Noccaea japonica. Frontiers in Plant

768 Science 11: 610.

769 Nkrumah PN, Baker AJM, Chaney RL, Erskine PD, Echevarria G, Morel JL, van der

770 Ent A. 2016. Current status and challenges in developing nickel phytomining: an 

agronomic perspective. Plant and Soil 406: 1-15. Thomine S. 2008. Functional characterization of NRAMP3 and NRAMP4 from the metal hyperaccumulator Thlaspi caerulescens. New Phytologist 181: 637-650. Pfaffl MW. 2001. A new mathematical model for relative quantification in real-time RTPCR. Nucleic Acid Research 29: 16-21. Pillon Y, Hopkins HC, Rigault F, Jaffre T, Stacy EA. 2014. Cryptic adaptive radiation in tropical forest trees in New Caledonia. New Phytologist 202: 521-530. Pillon Y, Munzinger J, Amir H, Lebrun M. 2010. Ultramafic soils and species sorting in the flora of New Caledonia. Journal of Ecology 98: 1108-1116. R Development Core Team. 2015. R: A Language and Environment for Statistical Computing. $R$ foundation for Statitical Computing: http://www.R-project.org/. global database for plants that hyperaccumulate metal and metalloid trace elements. New Phytologist 218: 407-411.

Ritchie ME, Phipson B, Wu D, Hu Y, Law CW, Shi W, Smyth GK. 2015. limma powers differential expression analyses for RNA-sequencing and microarray studies. Nucleic Acid Research 43: e47.

789 Robinson MD, McCarthy DJ, Smyth GK. 2010. edgeR: A Bioconductor package for 790 differential expression analysis of digital gene expression data. Bioinformatics 26: 139791140.

792 Roux J, Rosikiewicz M, Robinson-Rechavi M. 2015. What to compare and how:

793 Comparative transcriptomics for Evo-Devo (M Robinson-Rechavi, Ed.). Journal of 794 Experimental Zoology. Part B, Molecular and Developmental Evolution 324: 372-382.

795 Schaaf G, Honsbein A, Meda AR, Kirchner S, Wipf D, von Wiren N. 2006. AtIREG2 encodes a tonoplast transport protein involved in iron-dependent nickel detoxification in Arabidopsis thaliana roots. Journal of Biological Chemistry 281: 25532-25540.

798 Schwab R, Ossowski S, Riester M, Warthmann N, Weigel D. 2006. Highly Specific 799 Gene Silencing by Artificial MicroRNAs in Arabidopsis. The Plant Cell 18: 1121-1133.

800 Shahzad Z, Gosti F, Frérot H, Lacombe E, Roosens N, Saumitou-Laprade P, 801 Berthomieu P. 2010. The five AhMTP1 zinc transporters undergo different evolutionary 802 fates towards adaptive evolution to zinc tolerance in Arabidopsis halleri. PLoS Genetics 803 6: e1000911.

804 Simão FA, Waterhouse RM, loannidis P, Kriventseva E V, Zdobnov EM. 2015. 805 BUSCO: assessing genome assembly and annotation completeness with single-copy 806 orthologs. Bioinformatics 31: 3210-3212. 
807 Smith-Unna R, Boursnell C, Patro R, Hibberd J, Kelly S. 2016. TransRate: reference

808 free quality assessment of de novo transcriptome assemblies. Genome Research 26:

809 1134-1144.

810 Tsai HH, Schmidt W. 2017. Mobilization of Iron by Plant-Borne Coumarins. Trends in 811 Plant Science 22: 538-548.

812 Vacchina V, Mari S, Czernic P, Marques L, Pianelli K, Schaumloffel D, Lebrun M,

813 Lobinski R. 2003. Speciation of nickel in a hyperaccumulating plant by high-

814 performance liquid chromatography-inductively coupled plasma mass spectrometry and

815 electrospray MS/MS assisted by cloning using yeast complementation. Analytical

816 Chemistry 75: 2740-2745.

817 Verbruggen N, Hermans C, Schat H. 2009. Molecular mechanisms of metal

818 hyperaccumulation in plants. New Phytologist 181: 759-776.

819 Waldron KJ, Rutherford JC, Ford D, Robinson NJ. 2009. Metalloproteins and metal 820 sensing. Nature 460: 823-830.

821 Weber M, Harada E, Vess C, Roepenack-Lahaye E V, Clemens S. 2004. Comparative

822 microarray analysis of Arabidopsis thaliana and Arabidopsis halleri roots identifies

823 nicotianamine synthase, a ZIP transporter and other genes as potential metal 824 hyperaccumulation factors. Plant Journal 37: 269-281. 


\section{Figure legends}

827 Figure 1: Phylogenetic distribution of nickel hyperaccumulators. Eudicots Plant

828 families containing nickel hyperaccumulators are indicated in red on the phylogenetic 829 tree. The drawings illustrate the plant families and genera containing nickel 830 hyperaccumulators that we have sampled from France, New Caledonia and Cuba.

831 Figure 2: Cross-family comparative transcriptomics and orthologous group 832 annotation of genes convergently associated with nickel hyperaccumulation. (a) 833 Cross-species comparative transcriptomic reveals Differential Expressed (DE) genes 834 between nickel hyperaccumulator species (black) and related non-nickel accumulators 835 (grey). Genes (contigs) are plotted according to their mean level of expression (x-axis) 836 and their differential expression (y-axis) in the pair of species. The numbers of significant $837 \mathrm{DE}$ (red and blue dots) and non-DE genes are indicated $\left(\log _{2} \mathrm{FC}>1, F D R<0.05\right)$. (b) 838 Distribution of the 26 selected Cluster of Orthologous Groups (COGs) associated with 839 nickel hyperaccumulation according to their predicted function and their level of 840 expression in hyperaccumulators: COGs containing DE genes more expressed in nickel 841 hyperaccumulators belonging to at least 3 distinct plant families (up-regulated COGs) 842 are in red and COGs containing DE genes less expressed in nickel hyperaccumulators 843 (down-regulated) are in blue. (c) Heat-maps of contigs associated with the selected 844 COGs up-regulated in nickel hyperaccumulators from 5 distinct families. COGs 845 corresponding to Class I transposable elements are not presented. (d) Heat-maps of 846 contigs associated with down-regulated COGs. The color scale represents the 847 expression Fold change of contigs in pairwise comparative analysis. The grey color 848 represents the absence of contigs. Abbreviations: Ncfi (Noccaea caerulescens subsp. 849 firmiensis), Ncviv (N. caerulescens 'Viviez'), Nmon (N. montana), Pgra (Psychotria 850 grandis), Prev (P. revoluta), Pcos (P. costivenia), Pgab (P. gabriellae), Psem (P. 851 semperflorens), Gpru (Geissois pruinosa), Grac (G. racemosa), Hkan (Homalium 852 kanaliense), Hbet ( $H$. betulifolium), Lhav (Leucocroton havanensis), Lmic (Lasiocroton 853 microphyllus), IREG/FPN (Iron Regulated/ Ferroportin), UGT85A (UDP854 glucose:anthocyanidin/flavonol 3-O-glucosyltransferase), BAHD (BAHD 855 acyltransferase), CYP71 (Cytochrome P450 71), CYP704 (Cytochrome P450 704), FAR 856 (Fatty acyl-CoA reductase), SCPL (Serine carboxypeptidase), SSL (Strictosidine 857 synthase), WAKL (Wall associated receptor kinase like), GLP (Germin-like protein), COR 858 (Cold regulated gene), EXPA (Expansin), XTH (Xyloglucan 859 endotransglucosylase/hydrolase), PAE (Pectin acetylesterase), CESA (Cellulose 860 synthase), MLP (Major latex protein), JMT (Jasmonic acid carboxyl methyltransferase), 
861 GDSL (GDSL esterase/lipase), GULLO (L-gulonolactone oxidase), LTP (Bifunctional

862 inhibitor/lipid-transfer protein), DUF642 (DUF642 domain containing protein) and TPS

863 (Terpene synthase).

864 Figure 3. Nickel sensitivity of yeast cells expressing plant IREG/Ferroportin

865 transporters. Yeast cells expressing IREG/Ferroportin transporters cloned from $A$.

866 thaliana, N. caerulescens subsp. firmiensis, G. pruinosa and L. havanensis were plated

867 at different dilutions on a medium containing a toxic concentration of nickel for the control

868 line (transformed with pDR195 vector).

869 Figure 4. Nickel accumulation and NcIREG2 expression in various accessions of

870 Noccaea species. All plants were grown in hydroponic condition for 8 weeks in presence

871 of $37.5 \mu \mathrm{M} \mathrm{NiCl}_{2}$. (a) Nickel accumulation was measured in roots and shoots of Noccaea

872 caerulescens 'Viviez' (Ncviv), N. caerulescens subsp. firmiensis (Ncfi) and N. montana

873 (Nmon). Results are mean value \pm SD ( $n=3$ biological replicates). Letters denote

874 significant differences between accessions, with lowercase for roots and uppercase for

875 shoots (Tukey HSD test, $p<0.05$ ). (b) Quantitative RT-PCR analysis of NcIREG2

876 expression was performed on the same plants. NcIREG2 expression was corrected

877 using Nc6PGDH as a reference gene and normalized to 1 for the expression in Ncviv.

878 Relative expression is displayed with a log2 scale. Results are mean value \pm SD $(n=3$

879 biological replicates).

880 Figure 5. Localization and silencing of the IREG/Ferroportin transporter NcfiIREG2

881 (a) NcfilREG2 localizes on the vacuolar membrane in $N$. caerulescens cells. Confocal

882 picture of a transgenic line expressing NcfilREG2-GFP (green) in root cells. Cell wall was

883 stained with propidium iodide (magenta). The scale bar corresponds to $5 \mu \mathrm{m}$. (b)

884 Silencing of the IREG/Ferroportin transporter NcfilREG2 in roots of the nickel

885 hyperaccumulator $N$. caerulescens subsp. firmiensis reduces nickel accumulation. The

886 expression of NcfilREG2 was quantified by RT-qPCR (black bars) in 8 amiRNA

887 transgenic lines and control lines transformed with the pK7WG2D vector $(n=3)$ growing

888 in presence of $37.5 \mu \mathrm{M} \mathrm{NiCl}_{2}$ for 4 weeks. NcfilREG2 expression was corrected using

889 Ncfi6PGDH as reference gene and normalized to 1 for the expression in control lines.

890 Nickel concentration was measured in parallel in roots of the same lines by MP-AES

891 (green bars). (c) Correlation analysis between NcfilREG2 expression and nickel

892 accumulation. The quadratic correlation model showed positive correlation $\left(R^{2}=0.97^{* *}\right.$,

$893 P$-value $<0.001$ ) between NcfilREG2 expression and nickel accumulation in roots (black

894 dots) and non-significant correlation $\left(R^{2}=0.45\right)$ between NcfilREG2 expression in roots

895 and nickel accumulation in shoots (grey dots). 


\section{Tables}

898 Table 1. De novo assembled transcriptomes of nickel hyperaccumulators and 899 related non-nickel accumulator species\$

\begin{tabular}{|c|c|c|c|c|c|}
\hline Family/Species & $\begin{array}{l}{[\mathrm{Ni}]^{\#}} \\
(\mathrm{ppm})\end{array}$ & Origin & $\begin{array}{c}\text { Nbr. } \\
\text { contigs }\end{array}$ & $\begin{array}{l}\text { Assembly } \\
\text { size (Mbp) }\end{array}$ & $\begin{array}{l}\text { N50 } \\
\text { (bp) }\end{array}$ \\
\hline \multicolumn{6}{|l|}{ Brassicaceae - Noccaea } \\
\hline $\begin{array}{l}\text { Noccaea caerulescens } \\
\text { subsp. firmiensis (Ncfi) }\end{array}$ & 7580 & France & 41843 & 43.6 & 1735 \\
\hline N. caerulescens Viviez' (Ncviv) & 239 & France & $n a^{*}$ & $\mathrm{na}^{*}$ & $\mathrm{na}^{*}$ \\
\hline N. montana (Nmon) & 916 & France & 87243 & 48.8 & 692 \\
\hline \multicolumn{6}{|l|}{ Rubiaceae - Psychotria } \\
\hline Psychotria gabriellae (Pgab) & 17618 & New Caledonia & 60899 & 45.5 & 1140 \\
\hline P. semperflorens (Psem) & 34 & New Caledonia & 66755 & 49.8 & 1181 \\
\hline P. grandis (Pgra) & 15176 & Cuba & 45143 & 36.8 & 1344 \\
\hline P. costivenia (Pcos) & $1251^{\&}$ & Cuba & 46451 & 35.1 & 1240 \\
\hline P. revoluta (Prev) & 131 & Cuba & 56754 & 44.0 & 1245 \\
\hline \multicolumn{6}{|l|}{ Cunoniaceae - Geissois } \\
\hline Geissois pruinosa (Gpru) & 6239 & New Caledonia & 54969 & 42.1 & 1243 \\
\hline G. racemosa (Grac) & 132 & New Caledonia & 58386 & 43.7 & 1021 \\
\hline \multicolumn{6}{|l|}{ Salicaceae - Homalium } \\
\hline Homalium kanaliense (Hkan) & 6342 & New Caledonia & 52634 & 40.6 & 1259 \\
\hline H. betulifolium (Hbet) & 275 & New Caledonia & 49962 & 39.0 & 1294 \\
\hline \multicolumn{6}{|l|}{ Euphorbiaceae - Adelieae tribe } \\
\hline Leucocroton havanensis (Lhav) & 14073 & Cuba & 58990 & 44.4 & 1206 \\
\hline Lasiocroton microphyllus (Lmic) & 43 & Cuba & 52421 & 39.8 & 1244 \\
\hline
\end{tabular}

900 \$Details are provided in Supporting Information Table S1 and S2

901 \# Mean nickel concentration measured in leaves ( $n=2$, Table S1)

902 * not assembled: The transcriptome of Ncfi is used as a reference for Ncviv

903 \& Concentration likely underestimated because the samples were conserved in water-based RNAlater 
905 The following Supporting Information is available for this article:

906 Figure S1: Estimated time-divergence between species used in this study

907 Figure S2: Workflow used for RNA-Seq analyses

908 Figure S3: Additional MA-plot representation of cross-species comparative

909 transcriptomic analyses

910 Figure S4: Effect of the choice of the reference transcriptome on the identification of

911 Differentially Expressed genes

912 Figure S5: Molecular phylogeny of the plant IREG/Ferroportin family

913 Figure S6: Expression of IREG/Ferroportin orthologs in Homalium and Geissois species

914 Figure S7: The NcfilREG2-GFP fusion protein is functional in A. thaliana

915 Table S1: Metadata associated with plant samples

916 Table S2: RNA-Seq sequencing, assembly and mapping statistics

917 Table S3: Cluster of Orthologous Group analysis metrics

918 Table S4: Differentially Expressed Genes analysis

919 Table S5: List of Cluster of Orthologous Group associated with nickel hyperaccumulation

920 Table S6: List of primers.

921 Notes S1: References for Supporting Information

922 


\section{Page 31 of 35}

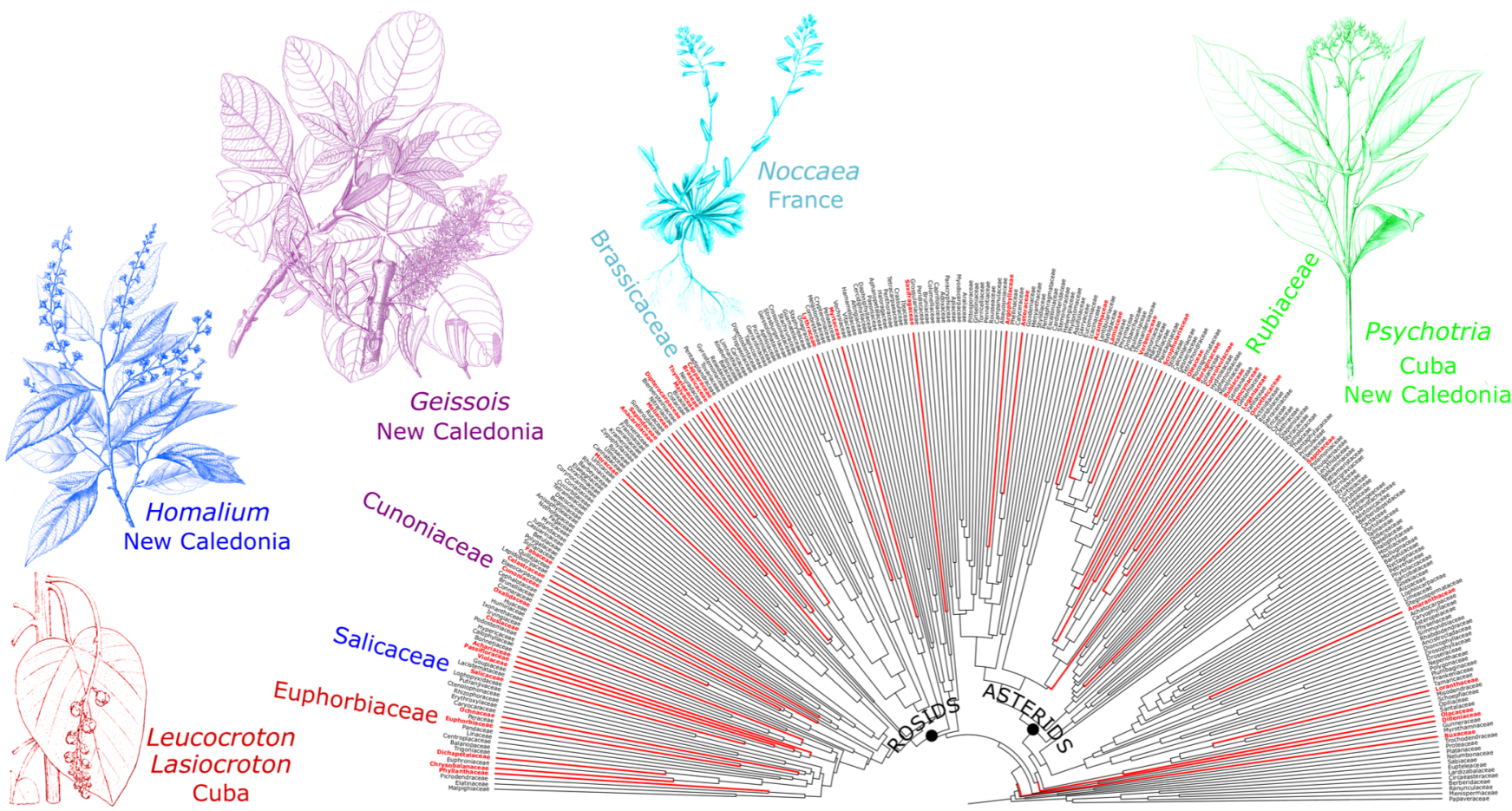



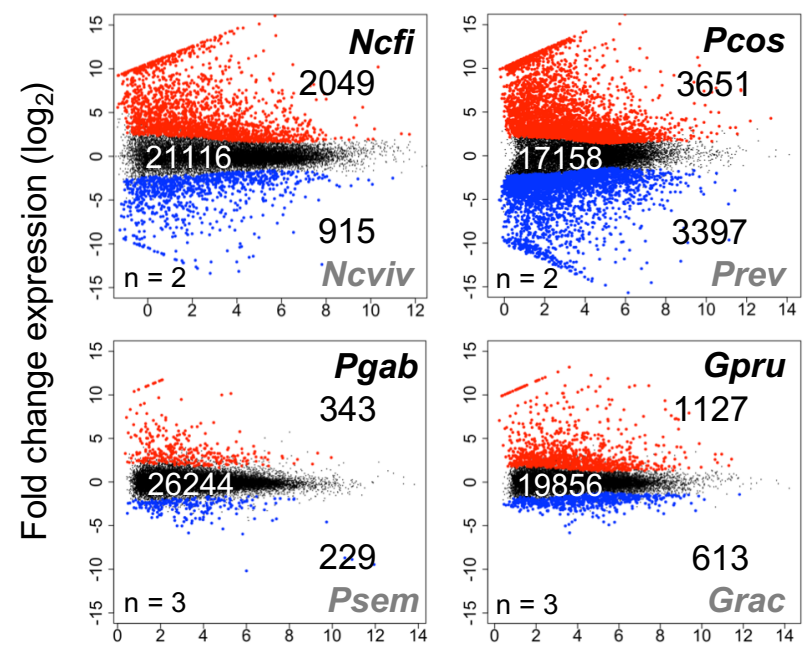

Number of COGs

Phenylpropanoids and other specialized metabolites

Class I Transposable elements

Metal transport and homeostasis

Cell wall biogenesis and organization

Response to biotic and abiotic stress

Others

Page 32 of 35

Average gene expression ( $\left.\log _{2} \mathrm{CPM}\right)$

(c)

(d)
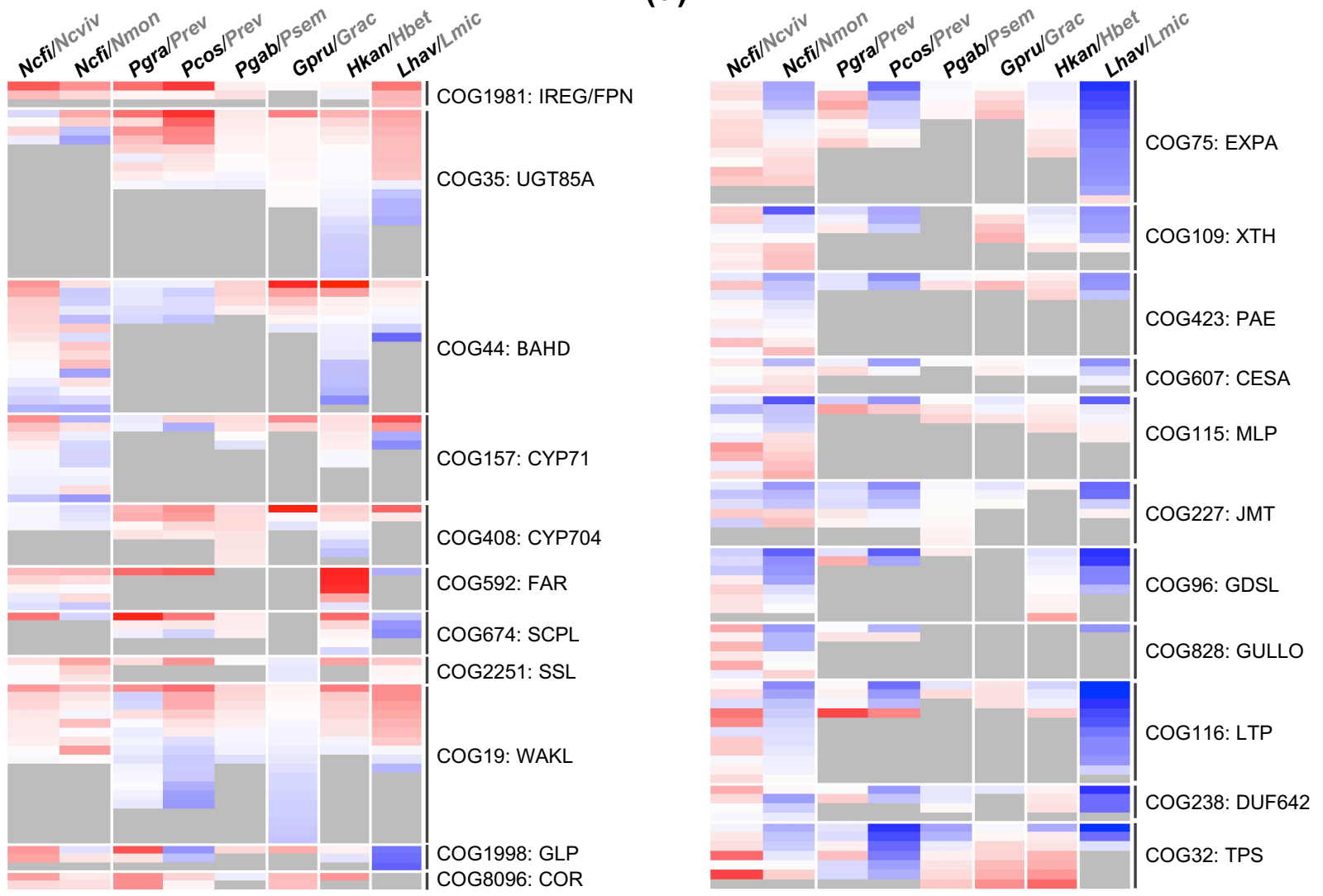

Expression value $\left(\log _{2} \mathrm{FC}\right)$

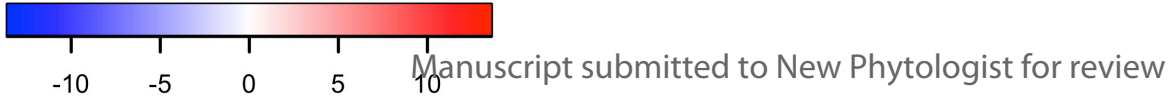

Figure 2 


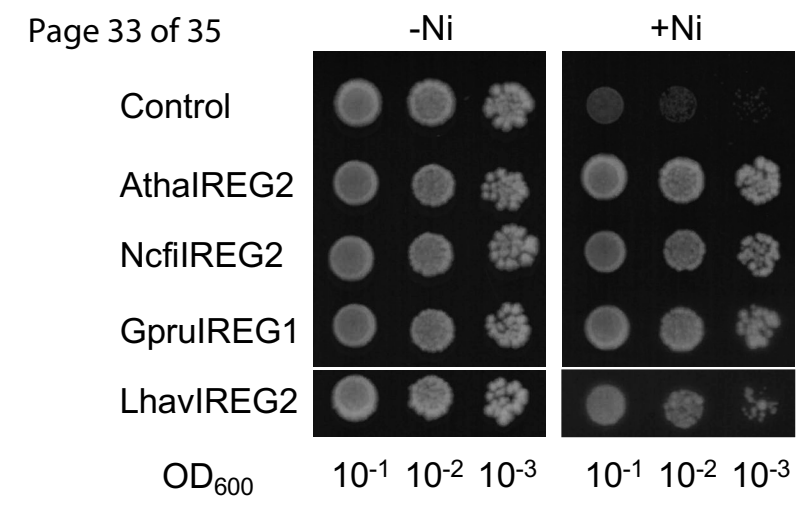

\section{Figure 3}




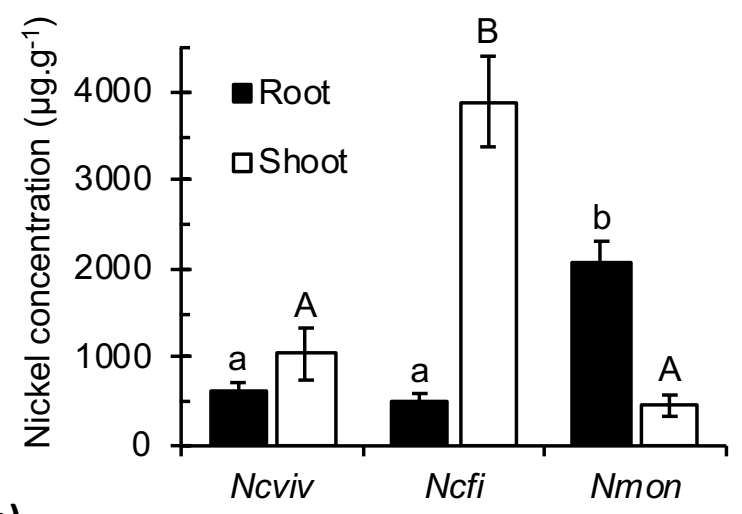

(b)

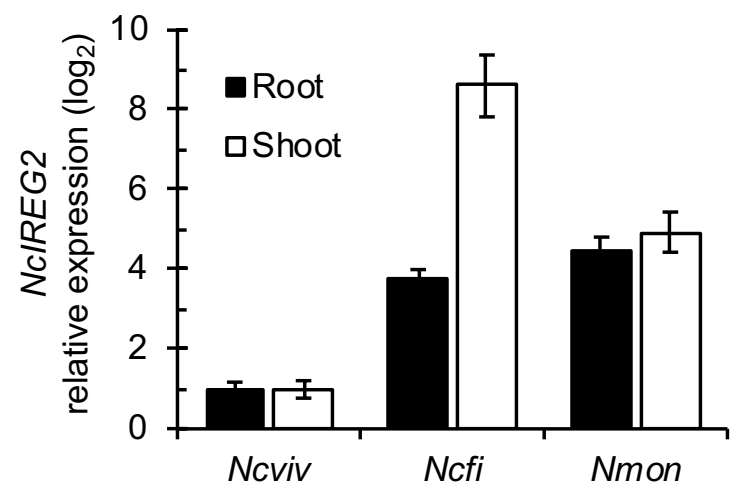


(a)

Page 35 of

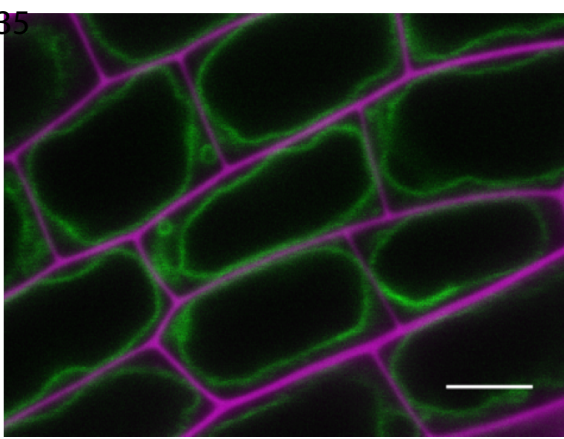

(b)

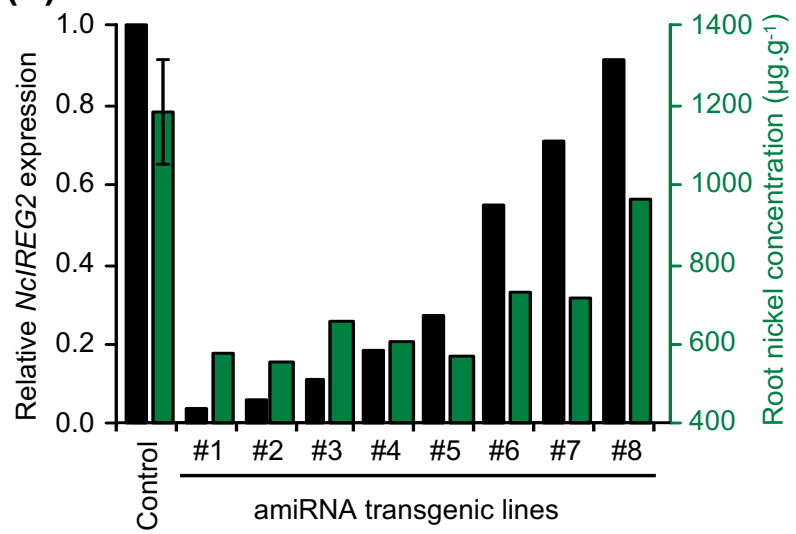

(c)

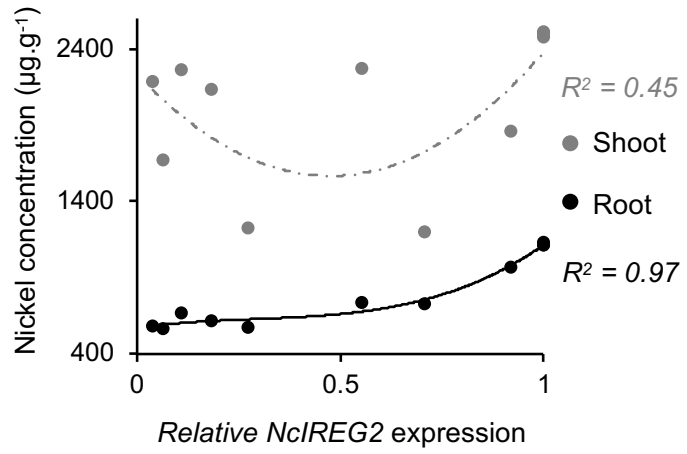

